\title{
高圧下の砂の応力〜ひずみ関係に関する一考察
}

\section{A CONSIDERATION ON THE STRESS-STRAIN RELATION OF A SAND UNDER HIGH PRESSURES}

\author{
三 浦 哲 彦* \\ By Norihiko MIURA
}

\section{1. まえがき}

土粒子が著しく破砕されるような応力条件の下では土 は特異な応力〜ひずみ挙動を示すことが知られている ${ }^{1)}$. このような場合の土の応力〜ひずみ関係を明らかにする ことは, 砂中の杭の挙動を解明したり, ぜい弱な土粒子 からなる土の安定性や支持力を解析する上で重要であ る.

さて，土の応力〜ひずみ関係に関する代表的な研究の 一つとして, 限界状態の概念に基づいた Roscoe らの研 究(2) がある. 彼らがおもに研究しているのは等方硬化 性を示す正規圧密粘土であり, Granta-gravel (剛塑性の 理想材料に対する呼び名), Cam-clay（弾塑性の理想材 料に対する呼び名）などのモデルを考え，これらに対す る応力〜ひずみ式を導いている. しかし, Schofield ら はその著書)の中で, 上記のモデルに対して導いた応力 〜ひずみ式は高圧下の砂に対しても適用できることを示 唆している.

筆者はこれまでに, 広範な圧力域での砂の力学的性質 を調べてきたが, Schofield らが示唆したように, 高圧下 の砂の応力〜ひずみ特性は低圧下の正規圧密粘土の応力 〜ひずみ特性によく類似していることが認められた ${ }^{5 /, 6)}$. 本文は, 既発表の豊浦砂に対するせん断試験結果 ${ }^{1}$ に基 ゔいて, Roscoe らが導いた式を適用すれば高圧下の砂 の応力〜ひずみ関係はおおよそ予測できることを示した ものである. なお, 土を対象に “高圧”といら場合には その具体的な圧力域を指定することは難しく, 便宜的に $10 \mathrm{~kg} / \mathrm{cm}^{2}$ 以上の圧力を指すこともあるが7)，ここでは 実験試料が，せん断中に著しい粒子破砕を生じるような 圧力といら意味で高圧としては $100 \mathrm{~kg} / \mathrm{cm}^{2}$ 程度以上の 圧力を, また低圧としては $10 \mathrm{~kg} / \mathrm{cm}^{2}$ 程度以下の圧力を 念頭においている.

\footnotetext{
* 正会員 工博 山口大学助教授 工学部土木工学科
}

\section{2. 限界状態と材料定数}

土の限界状態は有効平均主応力 $p$, 軸差応力 $q$ および 間隙比 $e$ の変化なしにせん断変形が進行する終局的状 態であって, 次の 2 式によって表わされる4).

$$
\begin{aligned}
& \Gamma=e+\lambda \ln p \\
& q=M p \ldots \ldots \ldots . . .
\end{aligned}
$$

ここに, $\lambda$ は $e \sim \ln p$ 図上における正規圧密曲線または 限界状態線の傾き, $\Gamma$ は限界状態線上の基準圧力に対応 寸る間隙比, また $M$ は限界状態に抢ける土の摩擦特性 を表わす材料定数である. $p$ および $q$ は有効主応力 $\sigma_{1}{ }^{\prime}$, $\sigma_{2}{ }^{\prime}, \sigma_{3}{ }^{\prime}$ を用いると三軸圧縮供試体 $\left(\sigma_{1}{ }^{\prime} \geq \sigma_{2}{ }^{\prime}=\sigma_{3}{ }^{\prime}\right)$ の 場合は $p=\left(\sigma_{1}{ }^{\prime}+2 \sigma_{3}{ }^{\prime}\right) / 3$ 扰よび $q=\sigma_{1}{ }^{\prime}-\sigma_{3}{ }^{\prime}$ となる.

以下に高圧下の砂の $p \sim q \sim e$ 関係について述べる.

\section{（1） $e \sim \ln p$ 関係}

豊浦砂の飽和密 詰 め供試体 (直径約 $50 \mathrm{~mm}$, 高さ約 $130 \mathrm{~mm}$, 初期間隍比 $\left.e_{0}=0.60\right)$ に対する繰返し等方圧 縮試験の結果は Fig. 1 に示すようであった. 高圧下の 砂の $e \sim \ln p$ 特性は時間依存性を示す ${ }^{8}$ が, 本実験は各 圧力下での体積変化の割合が $0.1 \mathrm{~cm}^{3} / \mathrm{hr}$ 以下になるま で圧縮（または膨張）させるという方法で行った．なお， 実験方法は文献 5) に詳述している.

Fig. 1 には, $e \sim \ln p$ 曲線の特徵を示すために, 等 方圧縮後の間隚比 $e_{c}$ と等方圧力 $p$ の関保 ${ }^{1}$ を理想化し て描いた曲線 (図中の破線) をあわせて示している.こ れより, 密ゔめ試料の $e \sim \ln p$ 曲線は, 理想化して考え ると $p=280 \mathrm{~kg} / \mathrm{cm}^{2}$ あたりで折点を有する直線で表わ され, 折点より高い圧力域では不可逆的な間隍比変化を 示し, また, 膨張曲線は可逆的間幥比変化を示すとみな すことができる. 折点より高い圧力域の不可逆的変化は 主として粒子破确に起因するものである ${ }^{9}$.

上述のような砂の $e \sim \ln p$ 特性は, 標準的圧密試験に 


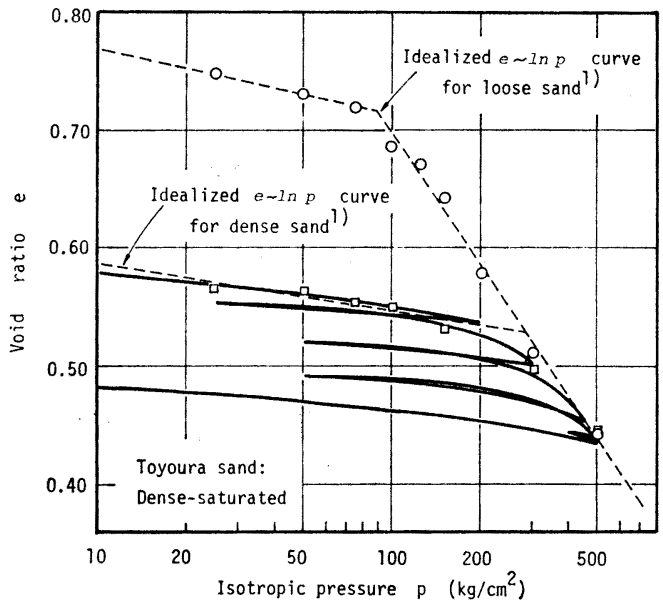

Fig. 1 Relation between void ratio $e$ and isotropic pressure $p$

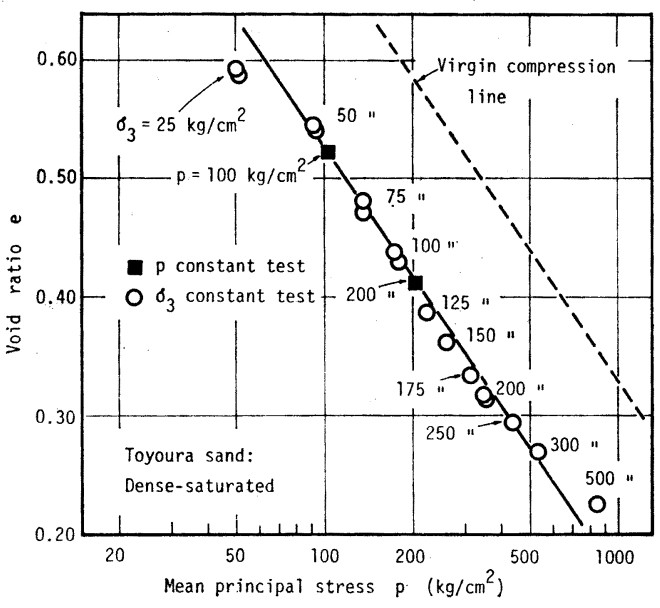

Fig. 2 Relation between void ratio $e$ and mean principal stress at failure $p$ in two kinds of drained triaxial compression tests

おいてみられる飽和粘土の $e \sim \ln p$ 特性とよく類似して いる. すなわち, 折点より高い圧力域の $e \sim \ln p$ 曲線は 粘土の正規圧密曲線に対応していると考えることができ る. その圧縮指数 $C_{c}\left(=\Delta e / \log _{10}\left(p_{2} / p_{1}\right)\right)$ は 0.37 とな る.

さて, 式 (1) の関係が満たされるかどらかを調べるた めに, 豊浦砂の拘束圧一定せん断試験 ${ }^{1)}$ おび平均主応 力一定試験において軸差応力が最大值に達したときを一 応限界状態と考え, そのときの間隚比と平均主応力の関 係をプロットしたのが Fig. 2 である. 同図の破線は，

Fig. 1 で理想化して描いた $e \sim \ln p$ 曲線の正規圧密領 城の部分を再び載せたものであり，プロット近傍の実線 は破線に平行に引かれている. 近似的に限界状態と考え 得る最大軸差応力時の $e \sim \ln p$ プロットが高圧域では正

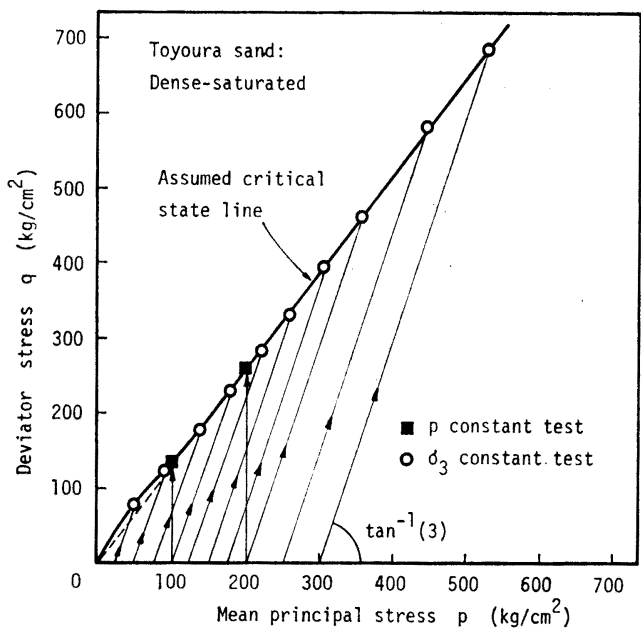

Fig. 3 Relation between deviator stress $q$ and mean principal stress $p$ at failure in two kinds of drained triaxial compression tests

規圧密線と平行であることから，式 (1) の関係は満たさ れていると考えてよいであろう。

\section{(2) $\quad \boldsymbol{p} \sim \boldsymbol{q}$ 関係}

拘束圧一定せん断試験および平均主応力一定試験の結 果を $p \sim q$ 図上にプロットするとFig. 3 のようにな る. 拘束圧一定試験の $\sigma_{3} \leqq 50 \mathrm{~kg} / \mathrm{cm}^{2}$ の場合を除けば, 各せん断試験における最大軸差応力時の $p \sim q$ 関係は応 力径路の違いによらず原点を通る直線上に載ることがわ かる.これより高圧下における砂の $p \sim q$ 関係は式 (2) の条件を満足すると考えられる.

\section{(3) 材 料 定 数}

Roscoe らが正規圧密粘土に対して導いた応力〜ひず み式においては， 3. で示すように 3 つの材料定数 $\lambda, \kappa$ および $M$ を用いている. 入 は先に述べたように $e \sim \ln p$ 曲線における正規圧密線の勾配によって, また， $た$ は同 じ $e \sim \ln p$ 曲線の膨張曲線の平均的勾配 (Fig. 1) によ って与えられる．また， $M$ は，Fig. 3 の限界状態線の 勾配から求めることができる. Table 1 は, 前述のよ5 にして求めた豊浦砂の 3 つの材料定数を数種類の粘土の 材料定数 ${ }^{4}$ と比較して示したものである. 材料定数の值

Table 1 Soil constants of the Toyoura sand compared with those of others")

\begin{tabular}{c|llll|l}
\hline Constants & $\begin{array}{l}\text { Klein } \\
\begin{array}{c}\text { Belt } \\
\text { Ton }\end{array}\end{array}$ & $\begin{array}{l}\text { Wiener } \\
\text { Tegel }\end{array}$ & $\begin{array}{l}\text { London } \\
\text { Clay }\end{array}$ & $\begin{array}{l}\text { Weald } \\
\text { Clay }\end{array}$ & $\begin{array}{l}\text { Toyoura } \\
\text { sand }\end{array}$ \\
\hline$\lambda$ & 0.356 & 0.122 & 0.161 & 0.093 & 0.162 \\
$\kappa$ & 0.184 & 0.026 & 0.062 & 0.035 & 0.018 \\
$\lambda / \kappa$ & 1.93 & 4.69 & 2.60 & 2.66 & 9.00 \\
$M$ & 0.845 & 1.01 & 0.888 & 0.95 & 1.30 \\
$G_{s}$ & 2.77 & 2.76 & 2.75 & 2.75 & 2.65 \\
\hline
\end{tabular}


からみて, 豊浦砂は 4 種類の粘土の中では Wiener Tegel $V$ にやや近い性状を有するように思われるが， $\lambda / \kappa$ の值は Wiener Tegel $V$ と比べてもかなり大きい.

\section{3. 応力〜ひずみ曲線}

\section{（1）応カ〜ひずみ式}

Table 1 に示したように，豊浦砂の $\kappa$ の值は スの $10 \%$ 程度の大きさであるので，ここでは $\kappa=0$ とする Granta-gravel 式と実験結果との比較検討は省略し, Cam-clay 式およびその修正式について実験結果との適 合性を調べることにする.

Cam-clay 式 (脚符 $c$ ) は次のように表わされている ${ }^{3)}$.

$$
\begin{aligned}
& \delta \varepsilon_{C}=\frac{\lambda-\kappa}{1+e}\left\{\frac{p \delta \eta+M \delta p}{M p(M-\eta)}\right\} \cdots \\
& \delta v_{C}=\frac{1}{1+e}\left(\frac{\lambda-\kappa}{M} \delta \eta+\lambda \frac{\delta p}{p}\right)
\end{aligned}
$$

また, Burland による仕事式

$$
\delta W=p \sqrt{\left(\delta \tau^{p}\right)^{2}+\left(M \delta \varepsilon^{p}\right)^{2}}
$$

を採用した修正式（脚符 $M$ ） は次の上うである゙)。

$$
\begin{aligned}
& \delta \varepsilon_{M}=\frac{\lambda-\kappa}{1+e}\left(\frac{2 \eta}{M^{2}-\eta^{2}}\right)\left(\frac{2 \eta \delta \eta}{M^{2}+\eta^{2}}+\frac{\delta p}{p}\right) \cdots \\
& \delta v_{M}=\frac{1}{1+e}\left\{(\lambda-\kappa) \frac{2 \eta \delta \eta}{M^{2}+\eta^{2}}+\lambda \frac{\delta p}{p}\right\} \cdots \cdots \cdots
\end{aligned}
$$

ここに， はせん断ひずみであり軸ひずみ $\varepsilon_{1}$ と体積ひ ずみ $v$ を用いて $\varepsilon=\varepsilon_{1}-(v / 3)$ と表わされる. また， は応力比で $\eta=q / p$ である.

式 (3)〜 (6) の応力〜ひずみ増分式に基ゔく応力〜ひ ずみ曲線と実験曲線とを比較検討するために, $d q=3 d p$ なる応力径路をとる排水せん断試験の場合を考える. こ のときは $\eta=q / p$ の微分式 $d q=\eta d p+p d \eta$ は $d p / p=$ $d \eta /(3-\eta)$ となるのでこれを式 (3)〜 (6) に代入して積 分すると以下の各式を得る.

$$
\begin{aligned}
\varepsilon_{C}= & \left(\frac{\lambda-\kappa}{1+e}\right)\left\{\frac{1}{3-M} \ln \left(\frac{3-\eta}{M-\eta}\right)\right. \\
& \left.-\frac{1}{M} \ln (M-\eta)+C_{1}\right\} \cdots \cdots \cdots \cdots \cdots \cdots(7) \\
v_{C}= & \frac{1}{1+e}\left\{\frac{\lambda-\kappa}{M} \eta-\lambda \ln (3-\eta)+C_{2}\right\} \cdots \cdots(8) \\
\varepsilon_{M}= & \frac{2(\lambda-\kappa)}{1+e}\left\{\overline{2} \frac{3}{M(3+M)} \ln (M+\eta)\right. \\
& -\frac{3}{2 M(3-M)} \ln (M-\eta)-\frac{1}{M} \arctan \left(\frac{\eta}{M}\right) \\
& \left.+\frac{3}{9-M^{2}} \ln (3-\eta)+C_{3}\right\} \cdots \cdots \cdots \cdots \cdots(9) \\
v_{M}= & \frac{1}{1+e}\left\{(\lambda-\kappa) \ln \left(M^{2}+\eta^{2}\right)-\lambda \ln (3-\eta)+C_{4}\right\}
\end{aligned}
$$

ここで積分定数は $\eta=0$ で $\varepsilon=v=0$ の条件より, $C_{1}=-$
$0.290, C_{2}=0.178, C_{3}=-0.343, C_{4}=0.103$ となる.

\section{（2）実測值と予測値の比較}

豊浦砂のひずみ制御排水せん断試験で得た応力〜ひず み曲線 ${ }^{1), 9}$ に基づいて $\eta \sim \varepsilon$ および $\eta \sim v$ 関係を求め, 式 (7)〜（10）で与えられる予測值と比較したのが Fig. 4 および Fig. 5 である. 式 (7)～10) で関係曲線を求め る場合に間幥比として圧密後の間隚比 $e_{c}$ を計算に用い るが, ここでは $e_{c}=0.50$ および $e_{c}=0.55$ の 2 つのケ ースについて実線および破線で示している.

まず，Fig. 4 の $\eta \varepsilon$ 関係については，実測值に対

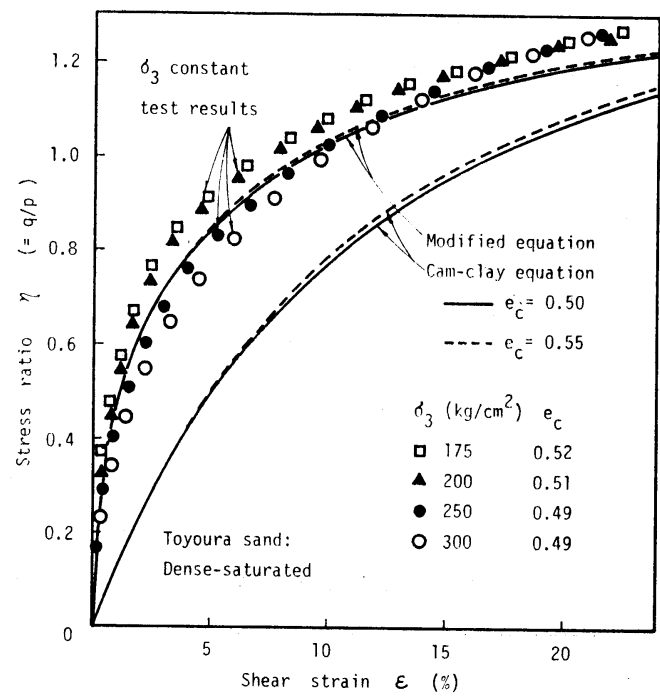

Fig. 4 Relation between stress ratio $\eta$ and shear strain $\varepsilon$ in $\sigma_{3}$ constant shear tests

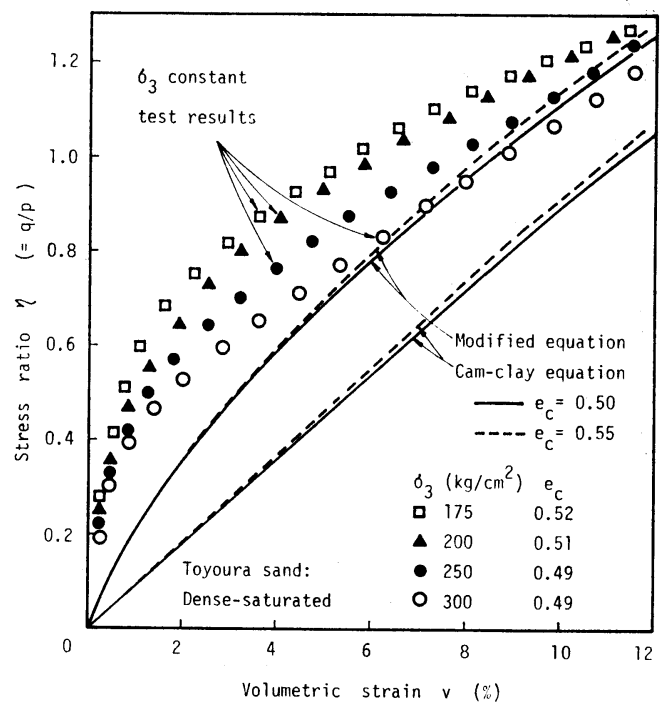

Fig. 5 Relation botween stress ratio $\eta$ and volumetric strain $v$ in $\sigma_{3}$ constant shear tests 
して Cam-clay 式はせん断ひずみ $\varepsilon$ を過大に評価するこ とになるが，修正式は $\varepsilon \leqq 20 \%$ の範囲では実測值に比 較的近い結果を与えている. また, $\eta \sim v$ 関係について は，体積ひずみが 10\% より小さい範囲では Cam-clay 式, 修正式のいずれも過大な $v$ の值を与えるが, 相対 的には修正式の方が実測值に近い結果となっている.

Fig. 4 および 5 に示した実測值において, 拘束圧が 低くなると予測值から次第に離れていく傾向が認められ る.これは， $\sigma_{3}=175 \mathrm{~kg} / \mathrm{cm}^{2}$ などではその等方圧密段階 における圧力レベルが低くて正規圧密線（Fig. 1 の理 想化 $e \sim \ln p$ 曲線では $280 \mathrm{~kg} / \mathrm{cm}^{2}$ 以上）に達していな いことと関係があると思われる．このように正規圧密線 まで到達しない拘束圧条件の試料については, それを過 圧密試料と考えて 過圧密状態に 対する応力〜ひずみ関 倸6)適用すれば実測值と予測值は近づくものと考えら れる.

拘束圧 $300 \mathrm{~kg} / \mathrm{cm}^{2}$ の場合の $q \sim \varepsilon_{1} \sim v$ 関係を示した のが Fig. 6 である.この図で $q \sim \varepsilon_{1}$ 関係に注目すると 実測值への適合性は Cam-clay 式よりは修正式の方がよ い上うである. 一方, $v \sim \varepsilon_{1}$ 関係については実測值はほ ぼ Cam-clay 式の曲線に沿って変化している. しかしこ れは, Cam-clay 式では $v$ と $\varepsilon_{1}(=\varepsilon+(v / 3))$ がともに 過大評価されたために生じた偶然の結果であると考える のが妥当であろう．上述のように，本実験試料に対する Cam-clay 式と修正式の適合性を比較する限りでは後者

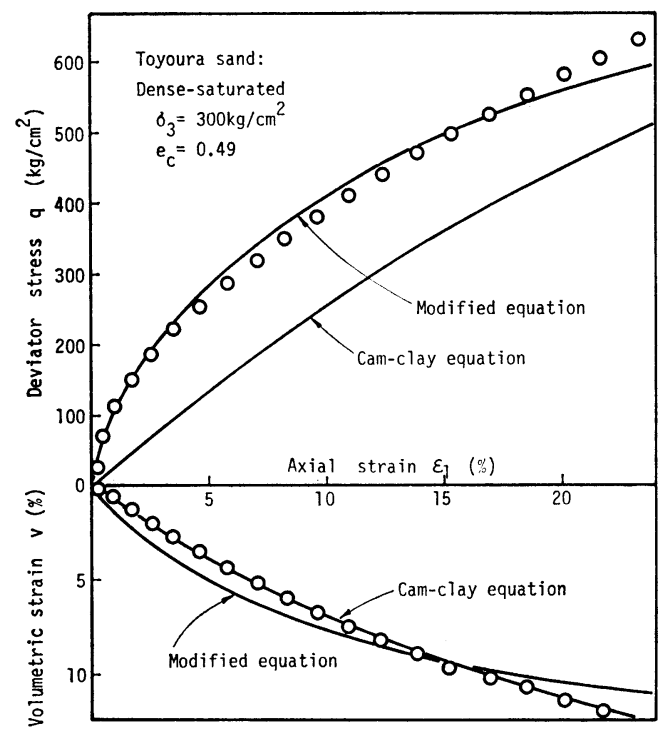

Fig. 6 Stress-strain relation of the Toyoura sand in a $\sigma_{3}$ constant shear test
の方がよい結果を与えるようである.しかしながら，本 文の検討結果からただちに両式の高圧下の砂の応力〜ひ ずみ挙動に対する適合性の優劣を結論するのは性急に過 ぎよう. 数種類の粒子破砕特性を異にする試料について さらに実験を行い，また，4．で述べる Cam-clay 式お よび修正式に含まれる種々の仮定について吟味した上で 両式の適合性を議論することが必要であり，その結果い っそう合理的な応力〜ひずみ式が得られるものと考え る.

\section{4. まとめ}

限界状態の概念に基づく Roscoe らの応力〜ひずみ式 は高圧下の砂の応力〜ひずみ関係を予測するのにも適用 できるとの前提に立って若干の検討を行い，この考えは 大筋において肯定できることを示し得たと考える.

今後の問題として, $e \sim \ln p$ 曲線の理想化による誤差 の評価, 材料の等方性を仮定することの妥当性, 降伏曲 面の形状と垂直条件の成否の確認などについて検討して いきたい.

終りに, 日頃からご指導賜っている九州大学 山内豊 聡教授, 本研究の端緒となる示唆を与えていただいた九 州大学 橋口公一博士に感謝の意を表します．また，本 研究は文部省科学研究費 (一般 (C)) の補助を受けた.

1）三浦哲彦・山内豊聡：高拘束圧下における標準砂の排水 せん断特性について, 土木学会論文報告集, No. 193, p. 69, 1971.

2) K.H. Roscoe, A.N. Schofield and A. Thurairajar : Yielding of Clays in States Wetter than Critical, Geotechnique, Vol. 13, No. 3, p. 211, 1963.

3) K.H. Roscoe and J.B. Burland : On the Generalized Stress-strain Behavior of "Wet" Clay, Engineering Plasticity, Cambridge Univ. Press, p. 535, 1968.

4) A.N. Schofield and C.P. Wroth : Critical State Soil Mechanics, McGraw-Hill Book Company, 1968.

5) 三浦哲彦・岡田 進：砂の応力〜ひずみ挙動について, 山口大学工学部研究報告, Vol. 26, No. 1, p. 35, 1975.

6）三浦哲彦・乗安直人・綾木和弘：高圧下におけるゆるい 砂の応力・ひずみ特性, 山口大学工学部研究報告, Vol. 27, No. 2, p. 61, 1977.

7）三浦哲彦 : 高压下に打りる粒状土の挙動, 土と基礎, Vol. 25 , No. 6, p. $67,1977$.

8）三浦哲彦・山内豊聡：高い等方圧力を受ける砂の圧縮特 性について, 土木学会論文報告集, No. 203, p. 45, 1972.

9) N. Miura and T. Yamanouchi : Effect of Water on the Behavior of a Quartz-Rich Sand under High Stresses, Soils and Foundations, Vol. 15, No. 4, p. 23, 1975.

(1978.3.30 - 受付) 